\title{
GTR Treatment in Furcation Grade II Periodontal Defects with the Recently Reintroduced Guidor PLA Matrix Barrier: A Case Series with Chronological Step-by-Step Illustrations
}

\author{
Anton Friedmann $\mathbb{D}^{1}$, Andreas Stavropoulos $\mathbb{D}^{2,3}$ and Hakan Bilhan $\mathbb{D}^{4}$ \\ ${ }^{1}$ Chair and Head Department of Periodontology, School of Dentistry, Faculty of Health, University of Witten, \\ Alfred-Herrhausen Str. 4458455 Witten, Germany \\ ${ }^{2}$ Chair and Head Department of Periodontology, Faculty of Odontology, University of Malmö, \\ Carl Gustafs väg 3420506 Malmö, Sweden \\ ${ }^{3}$ Division of Regenerative Dental Medicine and Periodontology, University Clinics of Dental Medicine, CUMD, University of Geneva, \\ Geneva, Switzerland \\ ${ }^{4}$ Department of Periodontology, School of Dentistry, Faculty of Health, University of Witten, \\ Alfred-Herrhausen Str. 4558455 Witten, Germany
}

Correspondence should be addressed to Hakan Bilhan; hakanbilhan@gmail.com

Received 1 April 2020; Revised 3 December 2020; Accepted 7 December 2020; Published 16 December 2020

Academic Editor: Pia L. Jornet

Copyright (c) 2020 Anton Friedmann et al. This is an open access article distributed under the Creative Commons Attribution License, which permits unrestricted use, distribution, and reproduction in any medium, provided the original work is properly cited.

\begin{abstract}
Molars with a furcation involvement (FI) exceeding grade 1 according to Hamp's classification are at approximately doubled risk of tooth loss. Guided tissue regeneration (GTR) is a regenerative approach in the treatment of periodontal defects and is aimed at achieving new clinical attachment formation. The aim of this case series was to assess the efficacy of a newly reintroduced polylactic acid (PLA) matrix barrier and to evaluate the feasibility of the surgical approach. 11 patients with an average age of 58.7 years were treated with GTR using a PLA matrix barrier. Patients were instructed not to brush and chew on the treated side for 4 weeks. A gentle clinical probing was performed after 6 months for the first time after surgery. The patients were included into individual maintenance program at three months' interval. The clinical improvement was expressed by reduced horizontal penetration of the probe accompanied by vast resolution of the vertical defect component. The change from grade II to grade I or complete resolution of the FI could be seen in 8 from 11 sites included. The newly reintroduced PLA matrix barrier showed promising results after a 12 -month observation period with clinical attachment gain.
\end{abstract}

\section{Introduction}

Periodontal attachment loss in the furcation area plays a pivotal role in the long-term prognosis of molars in both the mandible and the maxilla. Thus, molars with a furcation involvement (FI) exceeding grade 1 according to Hamp's classification seem to be at vast risk of tooth loss within a 5 -year observation period $[1,2]$. The presence of FI was shown to approximately double the relative risk of tooth loss for molars maintained in supportive periodontal therapy for up to 10-15 years. The risk increased obviously sharply looking at the maintenance rates after 15 years, although the authors pointed out the study heterogeneity [3]. Prognosis of FI teeth should also consider the vertical subcategorization into subclasses $\mathrm{A} / \mathrm{B} / \mathrm{C}$, which associates the case complexity with the infrabony extension of the periodontal pocket $[4$, 5]. The subclass $C$ representing the vertical extension of FI into the apical $1 / 3$ of the root length was shown to have the lowest ten-year survival rate in class II involved multirooted teeth. The subclasses A and B were associated with $91 \%$ and $67 \%$ survival rates over the same period, respectively [6]. The clinical long-term observations of the nonsurgical therapy followed by SPT lasting even for decades have been shown to leave the FI grade II without improvement and 


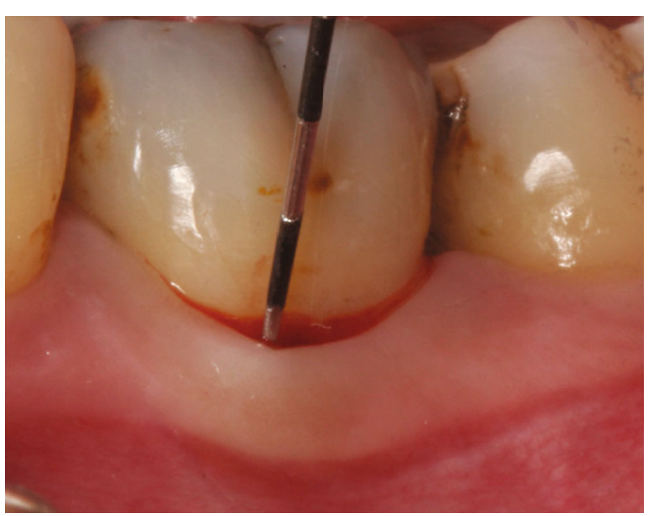

(a)

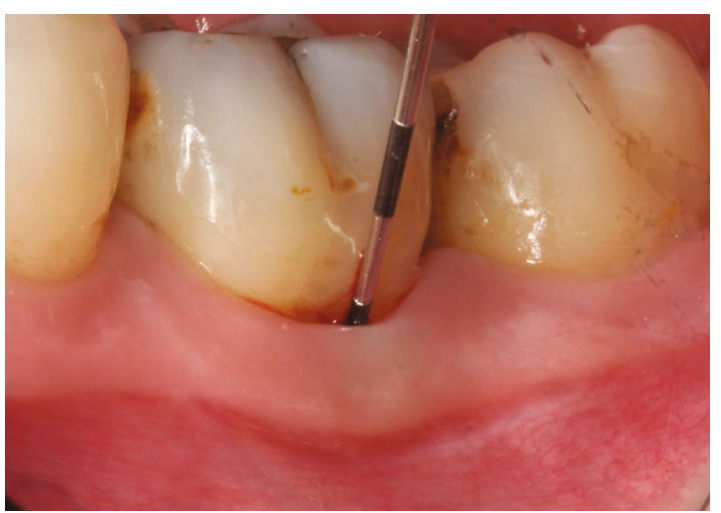

(c)

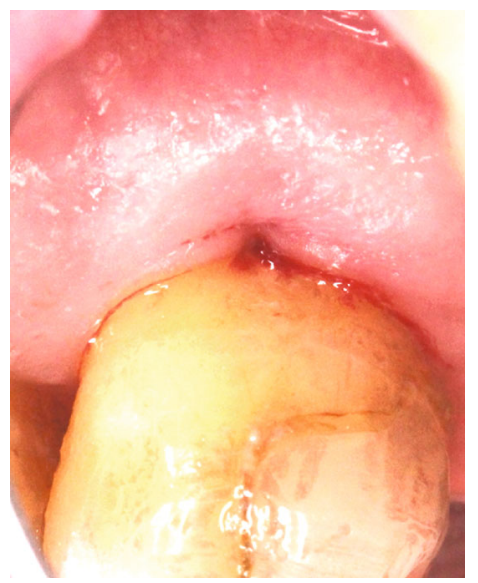

(e)

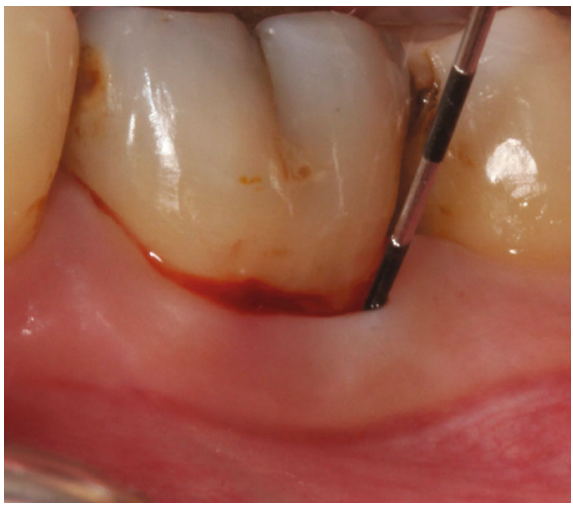

(b)

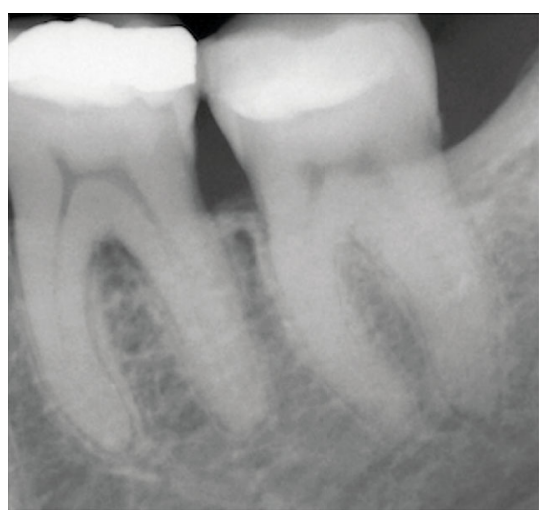

(d)

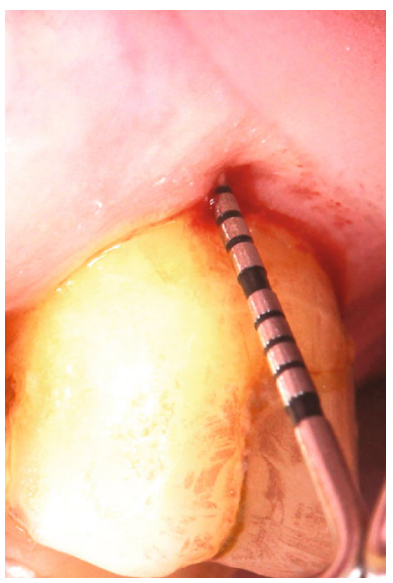

(f)

FIgure 1: Continued. 


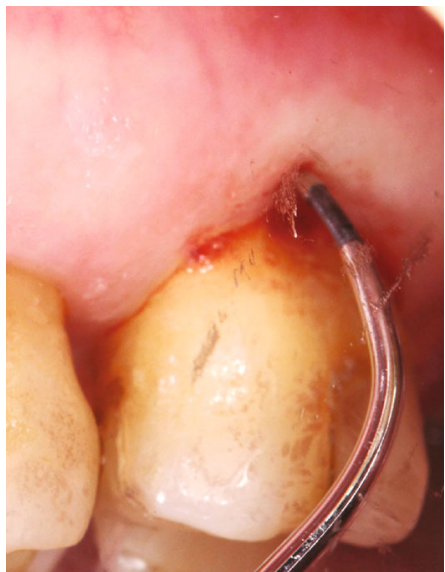

(g)

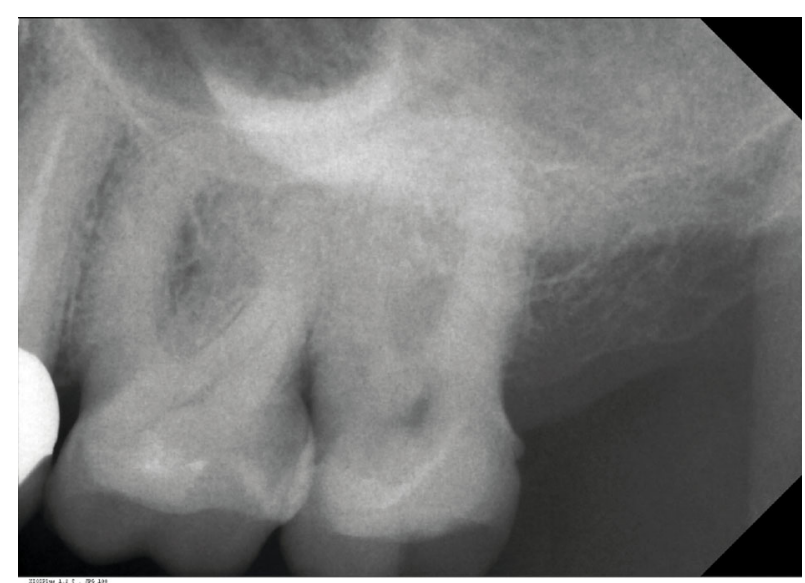

(h)

FIgURE 1: (a) Tooth 36 (FDI) baseline mesiobuccal VPD with 3 mm PPD F. (b) Tooth 36 (FDI) baseline distobuccal VPD with 3 mm PPD. (c) Tooth 36 (FDI) baseline $5 \mathrm{~mm}$ buccal VPD at the furcation entrance. (d) Tooth 36 (FDI) baseline periapical X-ray with furcation involvement grade 2. (e) Tooth 26 (FDI) baseline image of the gingiva margin at the furcation area. (f) Tooth 26 (FDI) baseline buccal $6 \mathrm{~mm}$ VPD at the furcation entrance. (g) Tooth 26 (FDI) baseline $6 \mathrm{~mm}$ HPD indicating buccal FI grade 2. (h) Tooth 26 (FDI) baseline periapical X-ray with furcation involvement grade 2 .

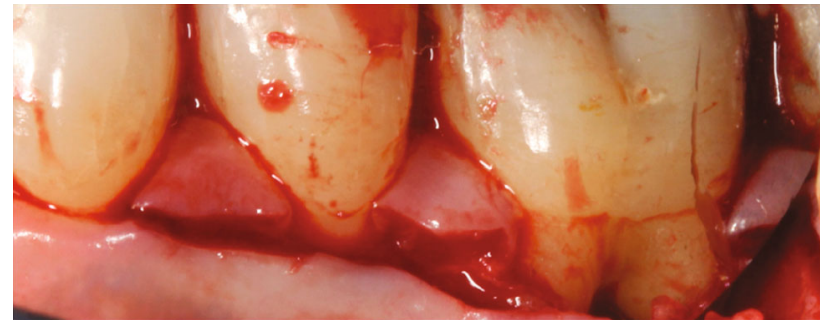

(a)

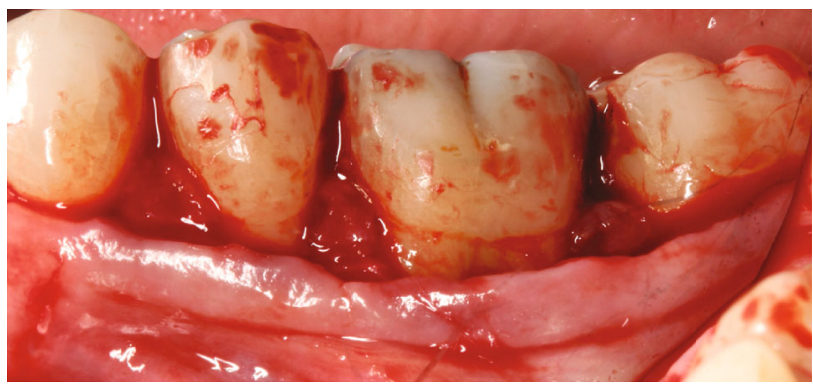

(c)

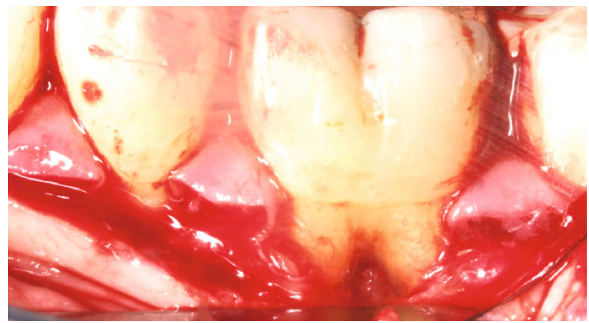

(b)

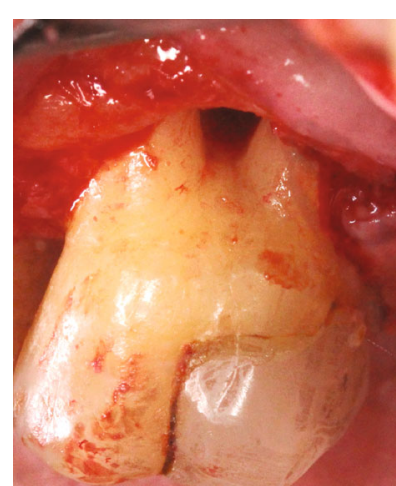

(e)

FIGURE 2: (a) The incision technique according to the modified papilla preservation method (MPTT) for accessing the buccal furcation in the mandibular molars (region 37-35). (b) Clinical image of the furcation defect after the preparation of the buccal full-thickness flap at tooth 36 which leaves the interproximal papillae in place. (c) The soft tissue preparation with deepithelized papillae prior to barrier insertion in the mandible. (d) Clinical image of the furcation area at tooth 26 before debridement after buccal full-thickness flap preparation with preserved papillae. (e) Clinical perspective of the furcation defect of tooth 26 after degranulation.

justify the surgical intervention [6]. Guided tissue regeneration (GTR) is a regenerative approach in the treatment of periodontal defects and is aimed at achieving new attachment formation in periodontally involved teeth $[7,8]$. Several systematic reviews have shown greater probing depth reduction, clinical attachment gain, and gain in hard tissue with GTR compared with open flap debridement in both intrabony and FI grade II defects [9] [10]. In this context, despite the observation that a complete furcation closure may rarely occur, the evidence points to the fact that GTR may often convert grade II furcation defects to grade I, which improves the long-term tooth prognosis [11].

The GTR technique relies on the use of a physical barrier to prevent epithelial downgrowth on the exposed root surface which is known to hinder the formation of new attachment components [12]. During the regenerative processes, protease 


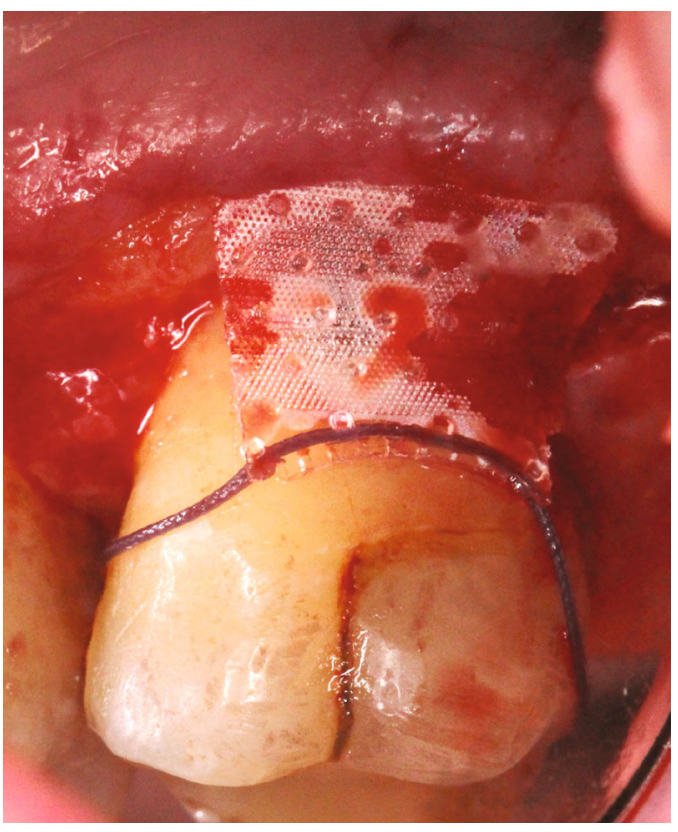

Figure 3: The Guidor matrix barrier in situ at the furcation entrance of tooth 26.

enzymes could harm, since tissues may not be completely mature in the beginning of healing [13]. The use of a physical barrier as a membrane helps the abovementioned matrix to mature undisturbed. Most of the resorbable periodontal membranes are subjected to proteolytic degradation over time, with the exception of the PLA barrier, which is degraded by hydrolysis instead of enzyme activity [14]. The PLA matrix barrier was reported to show positive results in previous case series published in the past [15-18]. The long-term stability achieved with the GTR technique using the PLA barrier has been reported for a period of 6 to 7 years previously [19].

In this case series, the authors report the outcomes in 11 consecutively treated patients by applying the Guidor matrix barrier using the MPPT protocol. The results obtained clinically and radiographically at 12 months are summarized.

\section{Clinical Procedures}

All 11 patients were selected from the pool of SPT patients of the department of periodontology at Witten/Herdecke University, Germany, and Malmö University, Sweden. Each patient had to have a comprehensive SRP treatment in the past followed by several SPT visits documenting general improvement of periodontal conditions by reduced FMPS and FMBS levels and decreased periodontal probing depths. All patients assigned to the GTR therapy were non- or exsmokers. The average age of the patients, 8 women and 3 men, was 58.7 years. Mandibular molars showing persistent FI grade 2 on the buccal or lingual aspect (Figures 1(a)1(d)) and maxillary molars with a buccal FI grade 2 (Figures $1(\mathrm{e})-1(\mathrm{~h})$ ) and representing either subclass A or B received GTR treatment using a Guidor ${ }^{\circledR}$ matrix barrier (GUIDOR $^{\circledR}$ Matrix Barrier-MSL (Molar Straight Large), Sunstar GmbH, Germany). This polymer is manufactured out of polylactides blended with a citric acid ester-compounds that have a history of more than 20 years of use in the food and medical industry.

All 11 cases were selected and treated by two periodontists (A.F. and A.S.), both calibrated regarding the surgical approach and GTR barrier. All surgeries were carried out under local anesthesia. The surgical approach was standardized. The Modified Papillae Preservation Technique (MPPT) was applied for incision and flap design (Figures 2(a)-2(c)) [20]. The papillae mesial and distal to the furcation treated were left in place without reflecting them. In the case of the distal molar, the sulcular incision was distally continued within the keratinized gingiva midcrestally in the edentulous zone. Vertical releasing incisions were not made. The buccal flap was reflected and released by a periosteal incision for coronal advancement before positioning the barrier. The root surfaces were thoroughly instrumented using Gracey curettes (Deppeler ${ }^{\circledR}$, Deppeler SA, Rolle, Switzerland) and/or ultrasonic instruments (EMS, Munich, Germany), and the defects (Figure 2(d)) were completely degranulated (Figure 2(e)). All but two defects were nongrafted to allow for blood clot formation and maturation inside the furcation defect. The very first two cases were grafted by either autogenous bone chips or by CopiOs (Zimmer Biomet Deutschland GmbH, Freiburg i. Breisgau, Germany). The barrier (Figure 3) was shaped into the size overextending the defect margins by 2 $3 \mathrm{~mm}$. The collar of the barrier was carefully adapted to the root trunk slinging the integrated suture around the tooth subgingivally (Figures 4(a) and 4(b)) and placing the knot to the opposite side of the tooth. The papillae were deepithelized using scalpel blade and scissors. The coronal advancement of the flap by releasing the periosteum ensured complete cover of the membrane barrier and tensionless suture using the modified vertical mattress technique with 4.0 PTFE monofilament suture (Biotex ${ }^{\circledR}$, Regedent, Dettelbach, Germany) $[15,17]$ (Figures 5(a)-5(c)). Moreover, the advanced flap margins were adjusted to completely cover the deepithelized papillae in a total incision extension.

The post-op regimen included patient's instruction to abstain from mechanical plaque control in the treated area for several weeks and to use Chlorhexidine (Chlorhexamed GlaxoSmithKline Consumer Healthcare GmbH \& Co. KG, Munich Germany) mouth rinse twice a day instead. Doxycycline $(200 \mathrm{mg} /$ day $)$ for duration of 10 days and analgesic medication (ibuprophen $600 \mathrm{mg} / 3 \mathrm{x}$ daily) on demand were administered; patients were rescheduled for weekly control visits. Sutures (Figures 6(a) and 6(c)) were removed after 14 days (Figures 6(b) and 6(d)), and the mouth rinse was thereafter substituted by the local use of Chlorhexidine gel (Chlorhexamed GlaxoSmithKline Consumer Healthcare GmbH \& Co. KG, Munich, Germany) in the wound area. Patients were instructed not to brush and chew on the treated side for another 4 weeks (Figure 7). Clinical images were taken at every control visit, and the X-ray was repeated at the end of the observation period after 12 and 18 months (Figure 8(e)) and 30 months, respectively (Figure $8(\mathrm{f})$ ). The gentle clinical probing was performed after 6 months for the first time after surgery. Nevertheless, the patients were included into individual maintenance program at three months' interval. 


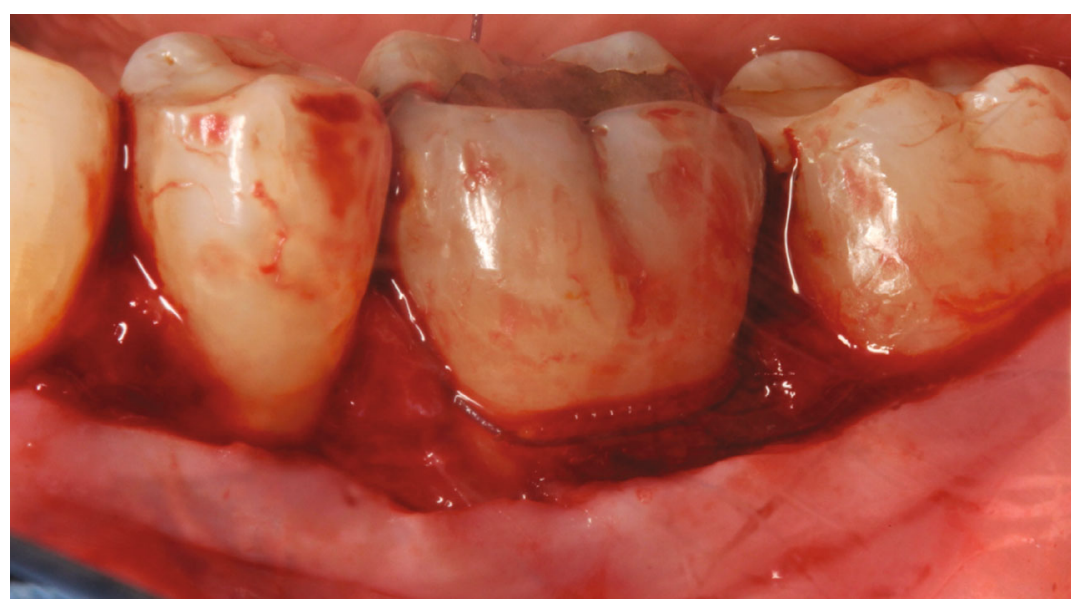

(a)

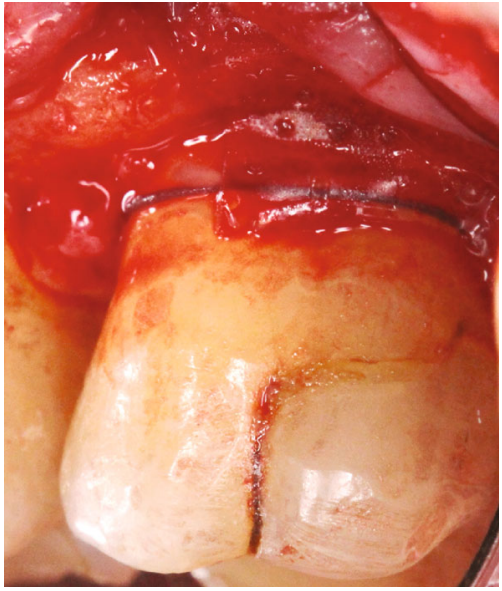

(b)

FIGURE 4: (a) The collar of the barrier carefully adapted to the root trunk slinging the integrated suture around the tooth placed subgingivally at tooth 36. (b) The collar of the barrier carefully adapted to the root trunk slinging the integrated suture around the tooth placed subgingivally at tooth 26.

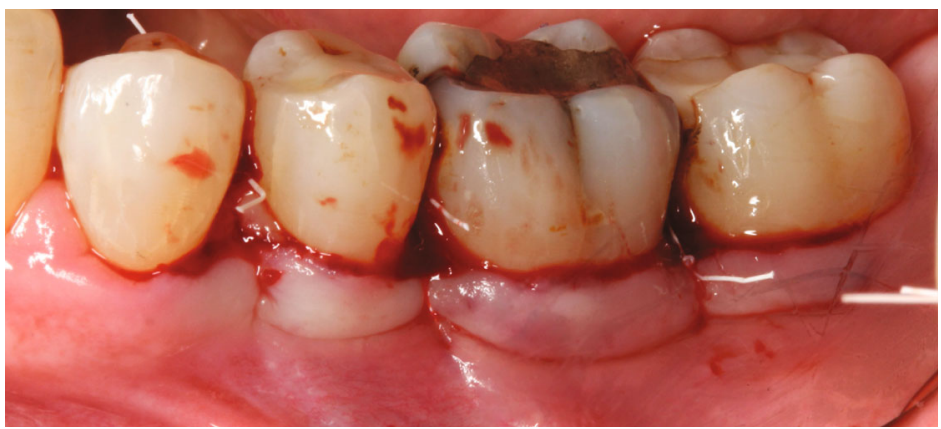

(a)

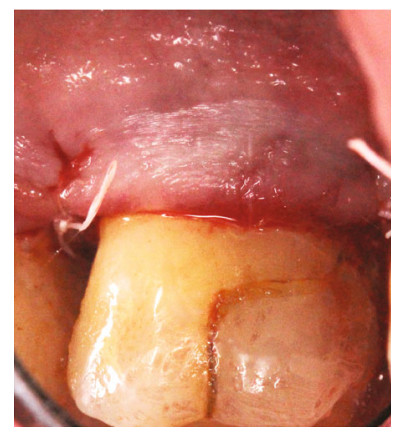

(b)

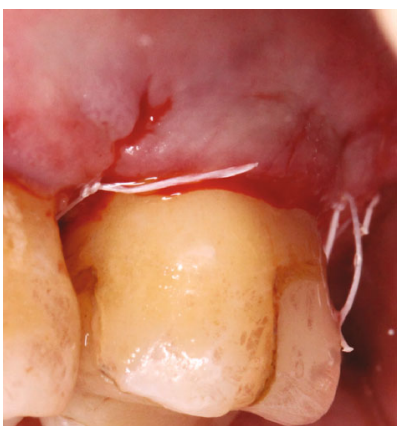

(c)

FIGURE 5: (a) The complete tensionless flap closure achieved by the coronally advanced flap (CAF) technique and the modified vertical mattress suture using PTFE 4.0 suture at tooth 36. The buccal aspect shows complete cover of the papillae and the barrier by the soft tissue. (b) The complete tensionless flap closure achieved by the CAF technique and the modified vertical mattress suture using PTFE 4.0 suture at tooth 26 . The buccal aspect shows complete cover of the papillae and the barrier by the soft tissue. (c) The mesial view at the coronally repositioned flap at tooth 26.

\section{Results and Discussion}

The clinical improvement was expressed by reduced horizontal penetration of the probe (Figures 8(a) and 8(c)) accompanied by vast resolution of the vertical defect component (Table 1) (Figures 8(b) and 8(d)), which also often could be followed radiographically (Figures $8(\mathrm{e})$ and $8(\mathrm{f})$ ). The change from grade II to grade I or complete resolution of the FI was assessed in 9 from 11 sites included (Table 1). Improvement of clinical outcomes for buccal grade II furcation defects by treatment with GTR and class II to class I furcation conversion is an utmost anticipated success criterion for more than 20 years [21-23]. The complete furcation closure had been achieved in $50 \%$ of molars with extensive bone loss [24]. 


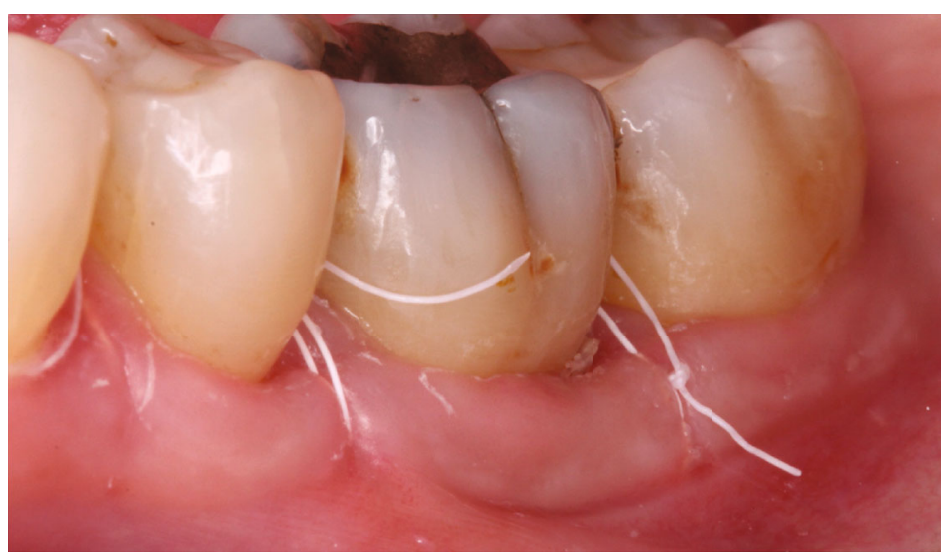

(a)

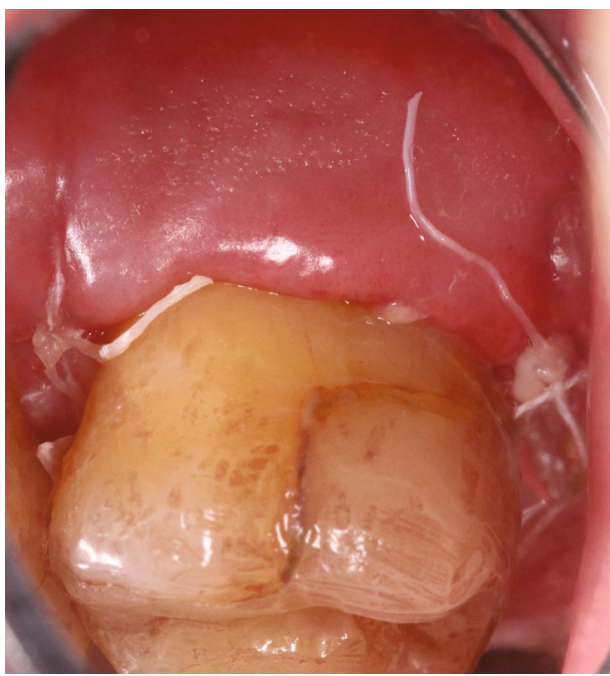

(c)

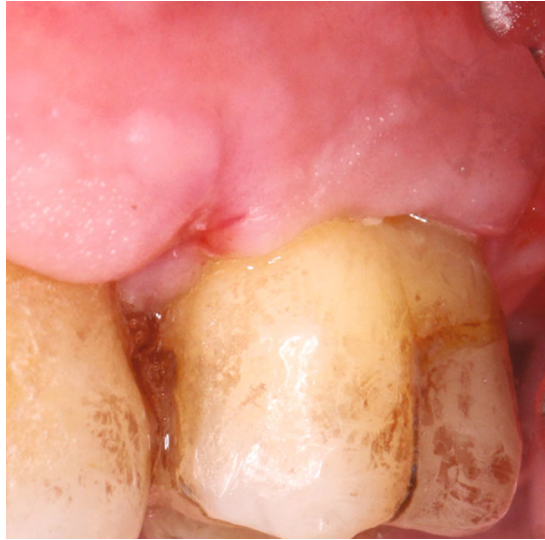

(b)

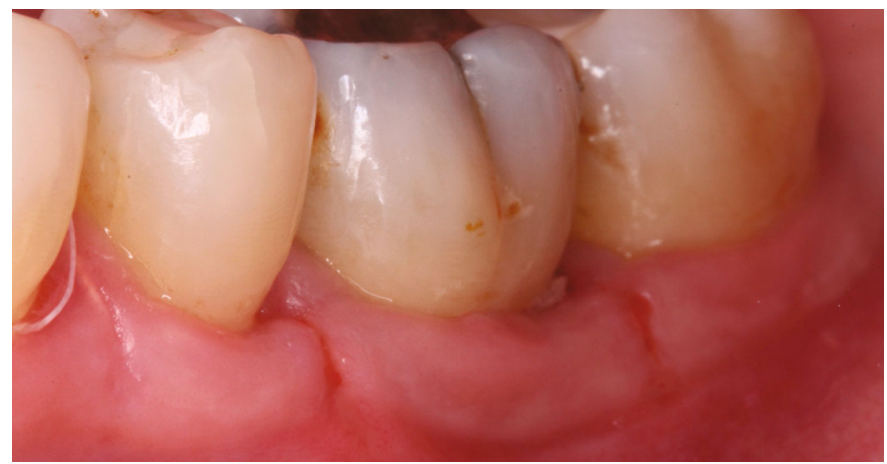

(d)

FIgURE 6: (a) Clinical image of tooth 36 at 2 weeks' visit indicates a minimal recession onset at the distal aspect before suture removal. (b) Clinical situation at tooth 36 after suture removal at the same visit. (c) Clinical situation 2 weeks post-op at tooth 26 shows complete cover of the barrier without any change in the level of the gingival margin before suture removal. (d) Dame visit, clinical situation after suture removal at tooth 26 , mesial view.

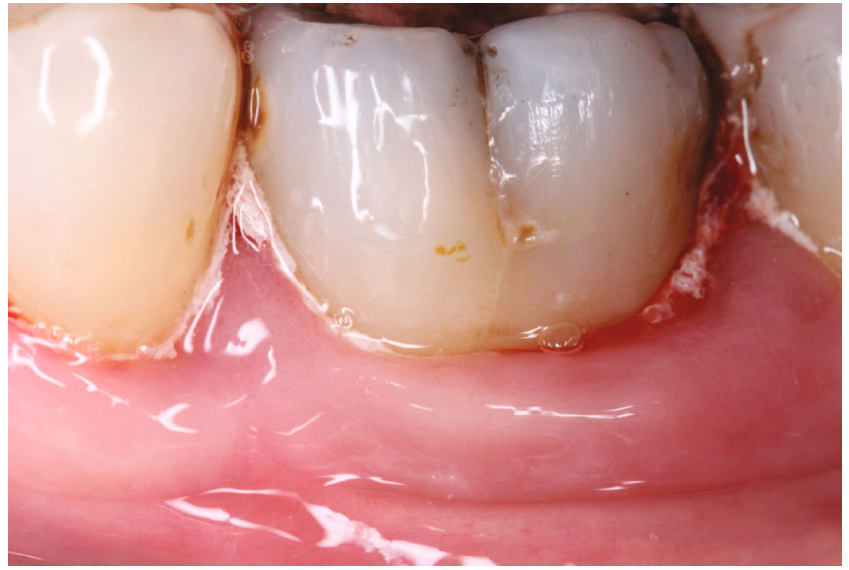

FIGURE 7: Four weeks' post-op image of tooth 36 , taken following a professional tooth cleaning session.
Although all FI defects were assigned to the subgroups A and $\mathrm{B}$, the improvement in vertical attachment level was considerable in all sites. Three teeth with initial FI grade II displayed almost unchanged horizontal attachment levels at the final examination visit 12 months after GTR surgery. Both of these nonresponding sites were characterized by unfavorable soft tissue position associated with a deep recession and an almost opened furcation fornix; all three teeth showed also a wide divergence angle of the roots. Local factors like these are known to be negative predictors for the regenerative outcome $[24,25]$.

The successful clinical closure of grade II furcations at 1 year following combination therapy with an ePTFE membrane and DFDBA had been shown [26, 27]. However, according to the properties of the barrier material, just two initially enrolled cases were grafted by autogenous bone chips or a bone substitute. Thereafter, the grafting of the furcation area was omitted.

The reviews of histological outcomes in GTR procedures published a decade ago as a recent one both demonstrated 


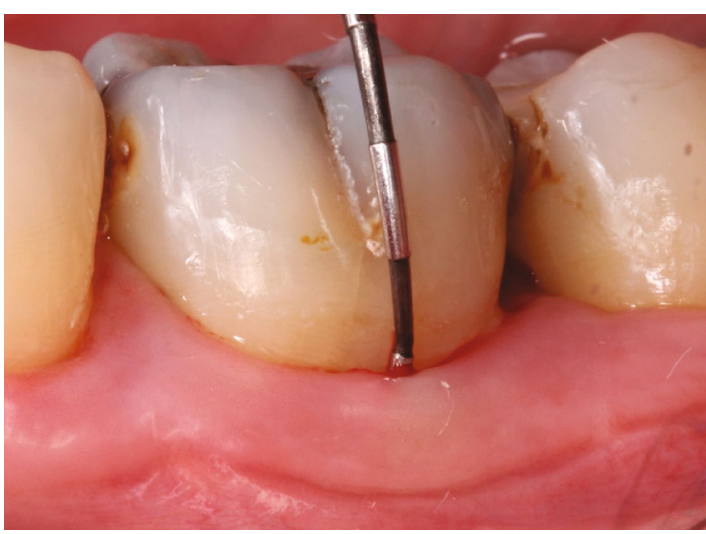

(a)

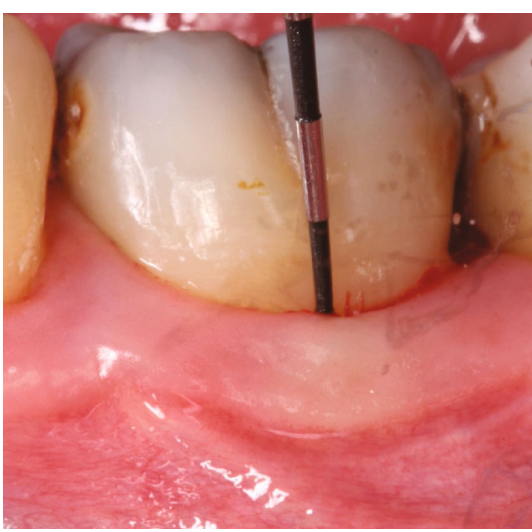

(b)

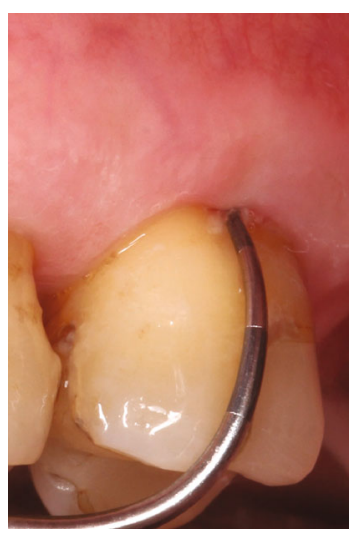

(c)

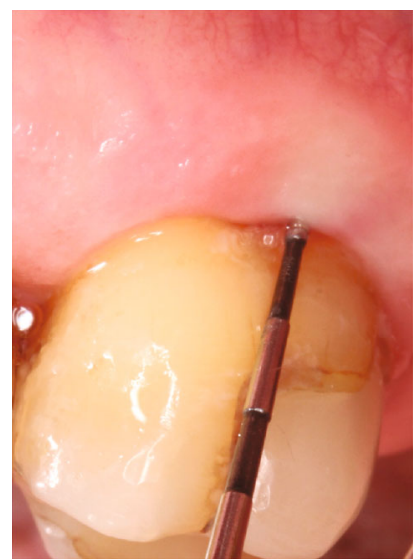

(d)

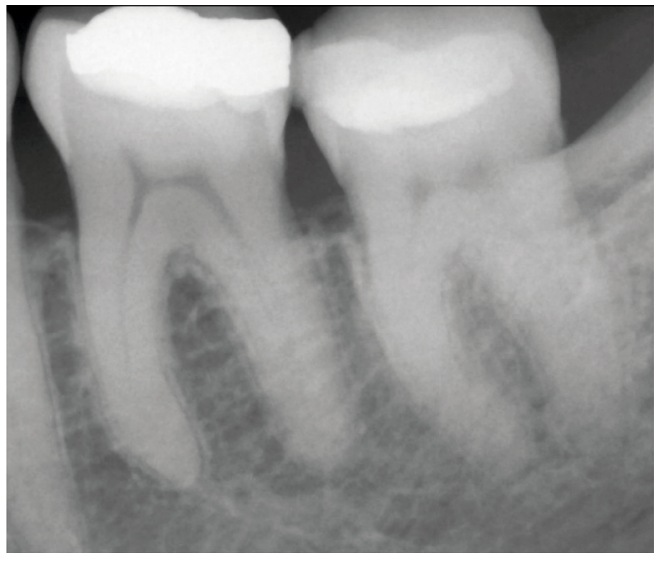

(e)

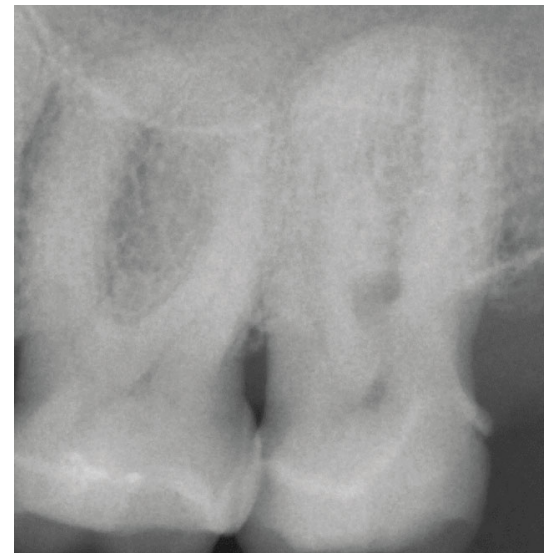

(f)

FIGURE 8: (a) Months' observation at tooth 36 reveals a $2 \mathrm{~mm}$ buccal HPD indicating the relevant improvement in the furcation area. (b) 12 month buccal VPD at 36 equals $3 \mathrm{~mm}$ depth, displaying a valuable improvement in vertical dimension. (c) 18-month observation displays a $3 \mathrm{~mm}$ of horizontal penetration depth (HPD) at tooth 26, indicating conversion from FI grade 2 to grade 1. (d) 18-month observation displays a $3 \mathrm{~mm}$ of vertical penetration depth (VPD) at tooth $26 \mathrm{n}$ from the buccal, indicating clinically relevant improvement in this dimension. (e) Periapical radiograph of tooth 36 after 12 months confirms clinical assessments and corroborates the improvement in the furcation area. (f) Periapical radiograph of tooth 26 after 30 months corroborates clinical measurements and confirms the success of the treatment.

favorable histologic healing after the use of a barrier membrane along with a grafting material and being superior to the results after open flap debridement $[28,29]$. The longterm observations confirm the stability of newly gained clinical attachment level over decades, once the treatment achieved sufficient attachment gain evaluated within first 6 to 12 months post-op [30].

The clinical effect in treating the degree II furcation with GTR including or excluding the bone grafting appears debatable. Studies which were looking at additional effect of a graft 
TABLE 1: Data showing patient details and outcome of the treatment.

\begin{tabular}{|c|c|c|c|c|c|c|c|c|c|c|c|c|c|c|c|c|}
\hline Pat. & Age & Tooth & & & Basel & & & Surgery & Graft +/- & & & $12 \mathrm{~mol}$ & nths & & & $\begin{array}{l}\text { BL- } \\
\text { no) }\end{array}$ \\
\hline Pat.+gender & Born & $\begin{array}{r}\text { (FDI } \\
+ \text { site) }\end{array}$ & PPD & REC & VAL & HAL & $\begin{array}{c}\text { FI } \\
\text { grade }\end{array}$ & Year & Type or 0 & PPD & REC & VAL & HAL & $\begin{array}{c}\text { FI } \\
\text { grade }\end{array}$ & VAL & HAL \\
\hline $1 / \mathrm{f}$ & 1966 & $47 \mathrm{~b}$ & 6 & 5 & 11 & 6 & II & $\begin{array}{l}\text { April } \\
2016\end{array}$ & Autogenous & 3 & 4 & 7 & 3 & I & +4 & +3 \\
\hline $2 / \mathrm{m}$ & 1954 & $37 \mathrm{~b}$ & 5 & 1 & 6 & 6 & II & $\begin{array}{l}\text { Nov. } \\
2016\end{array}$ & CopiOs & 3 & 2 & 5 & 3 & I & +1 & +3 \\
\hline $3 / f$ & 1963 & $47 \mathrm{~b}$ & 5 & 0 & 5 & 5 & II & Jan. 2017 & 0 & 2 & 1 & 3 & 1 & 0 & +2 & +4 \\
\hline $4 / \mathrm{f}$ & 1970 & $37 \mathrm{~b}$ & 4 & 1 & 5 & 4 & II & $\begin{array}{l}\text { Aug. } \\
2017\end{array}$ & 0 & 2 & 1 & 3 & 2 & I & +2 & +2 \\
\hline $5 / \mathrm{f}$ & 1956 & $36 \mathrm{~b}$ & 5 & 2 & 7 & 6 & II & Sep. 2017 & 0 & 2 & 1 & 3 & 2 & I & +4 & +4 \\
\hline $6 / f$ & 1950 & 46 ling & 6 & 0 & 6 & 6 & II & Sep. 2017 & 0 & 4 & 0 & 4 & 6 & II & +2 & 0 \\
\hline $7 / \mathrm{m}$ & 1957 & $46 \mathrm{~b}$ & 6 & 3 & 9 & 8 & II & Dec. 2017 & 0 & 3 & 5 & 8 & 6 & II & +1 & 0 \\
\hline $8 / \mathrm{m}$ & 1957 & $26 \mathrm{~b}$ & 6 & 4 & 10 & 8 & II & Dec. 2017 & 0 & 4 & 4 & 8 & 4 & II & +2 & +4 \\
\hline $9 / \mathrm{m}$ & 1955 & 46 ling & 6 & 2 & 8 & 6 & II & Jan. 2018 & 0 & 2 & 2 & 4 & 3 & I & +4 & +3 \\
\hline $10 / \mathrm{m}$ & 1955 & $26 \mathrm{~b}$ & 6 & 2 & 8 & 8 & II & Jan. 2018 & 0 & 3 & 2 & 5 & 3 & I & +3 & +5 \\
\hline $11 / \mathrm{f}$ & 1976 & 36 & 6 & 0 & 6 & 6 & II & 2017 & 0 & 3 & 0 & 3 & 3 & I & 3 & 3 \\
\hline$\varnothing$ & & & & & & & & & & & & & & & +2.6 & +2.8 \\
\hline
\end{tabular}

missed to show the level of statistically significant difference between the two options, indicating thereby that the additional effect for the combined treatment in intrabony and in furcation defects was underestimated $[11,31]$. Considering the mechanical properties of the PLA barrier such as stiffness and plasticity, both responsible for a valuable space maintaining capacity, no substitute material was used in most cases in the present series. Nevertheless, the GTR treatment regimen was successful in terms of clinical attachment gain in 8 of 11 furcation defects.

On the other hand, the space maintaining capacity of titanium-reinforced expanded polytetrafluoroethylene membranes was helpful even in reducing the negative impact of an unfavorable defect morphology as shown in a controlled clinical trial [32]. The PLA barrier, however, being biodegradable without a need of a reentry for membrane removal offers an obvious advantage over PTFE membranes. The integrated and degradable suture for fixing the barrier collar at the tooth neck appears an appropriate prerequisite for successful adaptation and immobilization of the barrier over the extension of the bony defect.

Numerous studies reported the MPPT as applied in all 10 cases effective in support of new attachment formation in infrabony and furcation defects $[20,33]$. The recession of gingival margin was estimated to extend for $1 \mathrm{~mm}$ more compared to the baseline assessment. This tendency was in agreement with the data published from several multicenter studies on GTR in infrabony and furcation defects [34, 35].

Several factors at the patient level as at tooth level may counteract with the healing and thereby impair the longterm outcome. Patient's lifestyle-related factors such as smoking, plaque control, and compliance with maintenance procedures are to consider as well as wound stability and disclosure of the barrier infection by periodontal pathogens from the oral cavity [36]. The initial healing was uneventful in all 11 patients resulting in primary wound closure and wound stability during the first weeks of post-op monitoring. Patient's compliance may retrospectively be accounted as high. None of them reported late complications in the treated area. The patient-related perception of the applied surgical method and the material used were in complete agreement with previously reported outcomes [37].

According to improvement of clinical attachment level with and without the use of bone substitute in 8 of 11 cases, the membrane stabilization may be considered as one of the key factors for successful regeneration. The utilized matrix barrier here with embedded suture and high level of plasticity despite certain rigidity gives the clinician the possibility to easier adapt the barrier upon the defect and stabilize it even neglecting the physical support by a bone substitute.

The results obtained clinically and radiographically at 12 and 18 months indicate the potential of the matrix barrier and the constraints of its sole use under complex conditions for achieving new clinical attachment in the furcation areas. However, the recent systematic review and the meta-analysis of surgical treatment options in FI multirooted teeth revealed superior outcome for the regenerative strategies in general when compared to conventional flap surgery [38]. Hence, the longterm stability of the results will depend on the patients' compliance. It is known that the clinical improvements after regenerative treatment can be preserved on a long-term basis on the majority of treated sites, provided that patients do not smoke, keep high oral hygiene standards, and regularly attend the SPT.

\section{Conclusions}

This case series confirms that sound clinical improvements can be in general achieved with the use of the Guidor matrix 
barrier as a regenerative treatment in furcation grade II defects. Further, the unsatisfactory results obtained in 2 cases herein also point to the limits of the procedure in complex situations with deficient amount of soft tissue and unfavorable root morphology.

\section{Abbreviations}

GTR: Guided tissue regeneration

FI: $\quad$ Furcation involvement

SPT: $\quad$ Supporting periodontal treatment

SRP: $\quad$ Scaling and root planing

MPPT: $\quad$ Modified Papillae Preservation Technique

PLA: $\quad$ Polylactic acid

CAL: Clinical attachment level

CHX: Chlorhexidine

ePTFE: Expanded polytetrafluoroethylene

DFDBA: Demineralized freeze-dried bone allograft

FMPS: $\quad$ Full mouth plaque score

FMBS: Full mouth bleeding score.

\section{Data Availability}

Data is available on request through the first author Prof. Dr. A. Friedmann. However, it should be noted that in Germany details about patients are restricted due to the data protection laws.

\section{Conflicts of Interest}

The authors declare that they do not have any commercial, proprietary, or financial interest in the products or companies described in this article.

\section{Authors' Contributions}

Prof. Dr. Anton Friedmann was responsible for the treatment of cases, figures, and manuscript preparation. Prof. Dr. Andreas Stavropoulos was responsible for contribution of a case and review of the manuscript. Dr. Hakan Bilhan was responsible for text editing and finalization of the manuscript.

\section{References}

[1] L. Nibali, A. Krajewski, N. Donos et al., "The effect of furcation involvement on tooth loss in a population without regular periodontal therapy," Journal of Clinical Periodontology, vol. 44, no. 8, pp. 813-821, 2017.

[2] S. E. Hamp, S. Nyman, and J. Lindhe, "Periodontal treatment of multirooted teeth. Results after 5 years," Journal of Clinical Periodontology, vol. 2, no. 3, pp. 126-135, 1975.

[3] L. Nibali, A. Zavattini, K. Nagata et al., "Tooth loss in molars with and without furcation involvement - a systematic review and meta-analysis," Journal of Clinical Periodontology, vol. 43, no. 2, pp. 156-166, 2016.

[4] D. Tarnow and P. Fletcher, "Classification of the vertical component of furcation involvement," Journal of Periodontology, vol. 55, no. 5, pp. 283-284, 1984.
[5] L. Nibali, C. Sun, A. Akcali, Y. C. Yeh, Y. K. Tu, and N. Donos, "The effect of horizontal and vertical furcation involvement on molar survival: a retrospective study," Journal of Clinical Periodontology, vol. 45, no. 3, pp. 373-381, 2018.

[6] M. S. Tonetti, A. L. Christiansen, and P. Cortellini, "Vertical subclassification predicts survival of molars with class II furcation involvement during supportive periodontal care," Journal of Clinical Periodontology, vol. 44, no. 11, pp. 1140-1144, 2017.

[7] S. Nyman, J. Lindhe, T. Karring, and H. Rylander, "New attachment following surgical treatment of human periodontal disease," Journal of Clinical Periodontology, vol. 9, no. 4, pp. 290-296, 1982.

[8] J. Gottlow, S. Nyman, T. Karring, and J. Lindhe, "New attachment formation as the result of controlled tissue regeneration," Journal of Clinical Periodontology, vol. 11, no. 8, pp. 494-503, 1984.

[9] I. G. Needleman, E. Giedrys-Leeper, R. J. Tucker, and H. V. Worthington, "Guided tissue regeneration for periodontal infra-bony defects," Cochrane Database of Systematic Reviews, vol. 3, no. 2, article CD001724, 1999.

[10] G. Avila-Ortiz, J. G. De Buitrago, and M. S. Reddy, "Periodontal regeneration - furcation defects: a systematic review from the AAP Regeneration Workshop," Journal of Periodontology, vol. 86, Supplement 2, pp. S108-S130, 2015.

[11] S. Jepsen, B. Heinz, K. Jepsen et al., "A randomized clinical trial comparing enamel matrix derivative and membrane treatment of buccal class II furcation involvement in mandibular molars. Part I: study design and results for primary outcomes," Journal of Periodontology, vol. 75, no. 8, pp. 1150-1160, 2004.

[12] D. Lundgren, L. Sennerby, H. Falk, B. Friberg, and S. Nyman, "The use of a new bioresorbable barrier for guided bone regeneration in connection with implant installation. Case reports," Clinical Oral Implants Research, vol. 5, no. 3, pp. 177-184, 1994.

[13] L. T. Grosso, D. K. Iha, J. Niu, R. C. Wakabayashi, and P. W. Johnson, "Protease profiles of cells isolated from regenerative membranes are associated with clinical outcomes," Journal of Periodontology, vol. 68, no. 9, pp. 809-818, 1997.

[14] J. Gottlow, "Guided tissue regeneration using bioresorbable and non-resorbable devices: initial healing and long-term results," Journal of Periodontology, vol. 64, Supplement 11, pp. 1157-1165, 1993.

[15] L. Laurell, H. Falk, J. Fornell, G. Johard, and J. Gottlow, “Clinical use of a bioresorbable matrix barrier in guided tissue regeneration therapy. Case series," Journal of Periodontology, vol. 65, no. 10, pp. 967-975, 1994.

[16] J. Gottlow, L. Laurell, D. Lundgren et al., "Periodontal tissue response to a new bioresorbable guided tissue regeneration device: a longitudinal study in monkeys," The International Journal of Periodontics \& Restorative Dentistry, vol. 14, no. 5, pp. 436-449, 1994.

[17] J. Gottlow, L. Laurell, A. Teiwik, and P. Genon, "Guided tissue regeneration using a bioresorbable matrix barrier," Practical Periodontics and Aesthetic Dentistry, vol. 6, no. 2, pp. 71-8; quiz 80, 1994.

[18] J. Gottlow, S. Nyman, J. Lindhe, T. Karring, and J. Wennstrom, "New attachment formation in the human periodontium by guided tissue regeneration. Case reports," Journal of Clinical Periodontology, vol. 13, no. 6, pp. 604-616, 1986.

[19] A. Stavropoulos and T. Karring, "Long-term stability of periodontal conditions achieved following guided tissue 
regeneration with bioresorbable membranes: case series results after 6-7 years," Journal of Clinical Periodontology, vol. 31, no. 11, pp. 939-944, 2004.

[20] P. Cortellini, G. Pini Prato, and M. S. Tonetti, “The modified papilla preservation technique with bioresorbable barrier membranes in the treatment of intrabony defects. Case reports," The International Journal of Periodontics \& Restorative Dentistry, vol. 16, no. 6, pp. 546-559, 1996.

[21] W. Becker, B. E. Becker, J. Mellonig et al., "A prospective multi-center study evaluating periodontal regeneration for class II furcation invasions and intrabony defects after treatment with a bioabsorbable barrier membrane: 1-year results," Journal of Periodontology, vol. 67, no. 7, pp. 641-649, 1996.

[22] R. C. V. Casarin, É. D. P. Ribeiro, F. H. Nociti et al., "A doubleblind randomized clinical evaluation of enamel matrix derivative proteins for the treatment of proximal class-II furcation involvements," Journal of Clinical Periodontology, vol. 35, no. 5, pp. 429-437, 2008.

[23] P. Cortellini and G. P. Prato, "Guided tissue regeneration with a rubber dam: a five-case report," The International Journal of Periodontics \& Restorative Dentistry, vol. 14, no. 1, pp. 8-15, 1994.

[24] G. M. Bowers, R. G. Schallhorn, P. K. McClain, G. M. Morrison, R. Morgan, and M. A. Reynolds, "Factors influencing the outcome of regenerative therapy in mandibular class II furcations: part I," Journal of Periodontology, vol. 74, no. 9, pp. 1255-1268, 2003.

[25] J. Horwitz, E. E. Machtei, P. Reitmeir, R. Holle, T. S. Kim, and P. Eickholz, "Radiographic parameters as prognostic indicators for healing of class II furcation defects," Journal of Clinical Periodontology, vol. 31, no. 2, pp. 105-111, 2004.

[26] M. R. Guillemin, J. T. Mellonig, and M. A. Brunsvold, "Healing in periodontal defects treated by decalcified freeze-dried bone allografts in combination with ePTFE membranes (I). Clinical and scanning electron microscope analysis," Journal of Clinical Periodontology, vol. 20, no. 7, pp. 528-536, 1993.

[27] M. R. Guillemin, J. T. Mellonig, M. A. Brunsvold, and B. Steffensen, "Healing in periodontal defects treated by decalcified freeze-dried bone allografts in combination with ePTFE membranes. Assessment by computerized densitometric analysis," Journal of Clinical Periodontology, vol. 20, no. 7, pp. 520527, 1993.

[28] A. Sculean, A. Kiss, A. Miliauskaite, F. Schwarz, N. B. Arweiler, and M. Hannig, "Ten-year results following treatment of intrabony defects with enamel matrix proteins and guided tissue regeneration," Journal of Clinical Periodontology, vol. 35, no. 9, pp. 817-824, 2008.

[29] O. Laugisch, R. Cosgarea, G. Nikou et al., "Histologic evidence of periodontal regeneration in furcation defects: a systematic review," Clinical Oral Investigations, vol. 23, no. 7, pp. 28612906, 2019.

[30] P. Cortellini, J. Buti, G. Pini Prato, and M. S. Tonetti, "Periodontal regeneration compared with access flap surgery in human intra-bony defects 20 -year follow-up of a randomized clinical trial: tooth retention, periodontitis recurrence and costs," Journal of Clinical Periodontology, vol. 44, no. 1, pp. 58-66, 2017.

[31] P. M. Trejo, R. Weltman, and R. Caffesse, "Treatment of intraosseous defects with bioabsorbable barriers alone or in combination with decalcified freeze-dried bone allograft: a randomized clinical trial," Journal of Periodontology, vol. 71, no. 12, pp. 1852-1861, 2000.
[32] M. S. Tonetti, G. Pini Prato, G. Stalpers, and P. Cortellini, "Guided tissue regeneration of deep intrabony defects in strategically important prosthetic abutments," The International Journal of Periodontics \& Restorative Dentistry, vol. 16, no. 4, pp. 378-387, 1996, 9242105.

[33] P. Cortellini and M. S. Tonetti, "Clinical and radiographic outcomes of the modified minimally invasive surgical technique with and without regenerative materials: a randomizedcontrolled trial in intra-bony defects," Journal of Clinical Periodontology, vol. 38, no. 4, pp. 365-373, 2011.

[34] R. Jaiswal and V. Deo, "Evaluation of the effectiveness of enamel matrix derivative, bone grafts, and membrane in the treatment of mandibular class II furcation defects," The International Journal of Periodontics \& Restorative Dentistry, vol. 33, no. 2, pp. e58-e64, 2013.

[35] J. Meyle, J. R. Gonzales, R. H. Bödeker et al., “A randomized clinical trial comparing enamel matrix derivative and membrane treatment of buccal class II furcation involvement in mandibular molars. Part II: secondary outcomes," Journal of Periodontology, vol. 75, no. 9, pp. 1188-1195, 2004.

[36] P. Eickholz, B. Pretzl, R. Holle, and T. S. Kim, "Long-term results of guided tissue regeneration therapy with nonresorbable and bioabsorbable barriers. III. Class II furcations after 10 years," Journal of Periodontology, vol. 77, no. 1, pp. 88-94, 2006.

[37] M. S. Tonetti, I. Fourmousis, J. Suvan et al., "Healing, postoperative morbidity and patient perception of outcomes following regenerative therapy of deep intrabony defects," Journal of Clinical Periodontology, vol. 31, no. 12, pp. 1092-1098, 2004.

[38] S. Jepsen, S. Gennai, J. Hirschfeld, Z. Kalemaj, J. Buti, and F. Graziani, "Regenerative surgical treatment of furcation defects: a systematic review and Bayesian network metaanalysis of randomized clinical trials," Journal of Clinical Periodontology, vol. 47, Supplement 22, pp. 352-374, 2020. 